\title{
PENGUJIAN PIROLISIS KAYU DENGAN METODE HAMPA UDARA UNTUK MEMPRODUKSI BAHAN BAKAR GAS
}

\author{
Yusrizal $^{1}$, Muhammad Idris ${ }^{2}$ \\ ${ }^{I}$ Dosen Program Studi Teknik Mesin Politeknik Aceh Selatan, Tapaktuan \\ ${ }^{2}$ Dosen Program Studi teknik Mesin STT Harapan Medan \\ ${ }^{1}$ E-Mail : Yusrizalmt@gmail.com
}

\begin{abstract}
Climate change, global warming and energy crisis are issues very worried in the world currently, so should be found a solution quickly and sustainably. Alternative energy and renewable energy is one alternative to completion of the issues. Research and development of methods for completion of the issues is very essential to be able immediately replace fossil fuels such as oil, gas and coal. United States, EU and Japan have invested their massive budgets to develop renewable energy technologies for biomass. They are targeting large-scale commercial manufacturing base and global. Additionally, in the developing countries, especially isolated village areas access to electricity not been evenly distributed. For reducing or prevent the effects of global warming and increase the electricity in isolated village areas, it would require a new technology for rubber wood pyrolysis. This technology created with little cost and easy maintenance in operation order to produce a clean fuel gas. The gas fuel can be used directly with a Generator Set are developed in laboratory scale. This journal informs about the performance of the plants and the influence of some parameters. The results of this research can be concluded that the new technology is feasible for implemented in remote rural areas are does not able to access electricity and improvement the performance of these plants enable the development of better.
\end{abstract}

Keywords: Pirolisys; Rubber wood; vacuum; gas

\begin{abstract}
Abstrak
Perubahan iklim, pemanasan global dan krisis energi merupakan isu yang sangat mengkhawatirkan di dunia pada saat ini, sehingga harus dicarikan solusi secara cepat dan berkelanjutan. Energi alternatif dan energi terbarukan merupakan salah satu alternatif untuk penyelesaian persoalan tersebut. Penelitian dan pengembangan metode untuk penyelesaian persoalan tersebut merupakan hal yang sangat penting untuk dapat segera menggantikan bahan bakar fosil seperti minyak, gas dan batu bara. Negara Amerika Serikat, Uni Eropa dan Jepang sudah menginvestasikan anggaran yang sangat besar untuk mengembangkan teknologi energi terbarukan untuk biomassa. Mereka menargetkan basis pabrik komersial skala besar dan global. Di samping itu, di negara-negara berkembang, terutama daerah desa terpencil akses untuk mendapatkan listrik belum semua merata. Untuk mengurangi atau mencegah dampak pemanasan global dan meningkatkan kelistrikan di daerah desa terpencil, maka diperlukan sebuah teknologi baru untuk pirolisis kayu karet. Teknologi ini dibuat dengan biaya yang murah dan pemeliharaan yang mudah dalam pengoperasiannya untuk bisa menghasilkan bahan bakar gas yang bersih. Bahan bakar gas tersebut bisa digunakan langsung dengan Generator Set yang dikembangkan dalam skala laboratorium. Jurnal ini menginformasikan kinerja alat dan pengaruh beberapa parameter kinerjanya. Hasil penelitian ini dapat disimpulkan bahwa teknologi baru ini layak intuk diterapkan di daerah desa terpencil yang tidak dapat mengakses listrik dan peningkatan kinerja alat ini sangat memungkinkan untuk dikembangkan lebih baik lagi.
\end{abstract}

Kata kunci: Pirolisis; Kayu karet; hampa udara; bahan bakar gas

\section{Pendahuluan}

Dua isu global yang sering diperbincangkan dunia dan masyakarat indonesia adalah mengenai pemanasan global dan krisis energi. Krisis energi yang dampaknya langsung bisa dirasakan adalah fluktuatifnya harga bahan bakar. Hal ini dipengaruhi oleh kenyataan bahwa kebutuhan terhadap bahan bakar semakin meningkat pesat, sementara itu sumber bahan baku fosil di alam makin berkurang. Konsekuensinya adalah tanpa energi masyarakat akan kembali ke jaman purba kala. Selain itu, penggunaan bahan bakar fosil juga berdampak bagi bumi kita. Penggunaan bahan bakar dari minyak dan batu bara disinyalir sebagai penyebab utama terjadinya pemanasan global. Pada situasi demikian, pirolisis biomassa telah mendapat perhatian yang sangat besar dan juga penelitian tentang pirolisis semakin gencar dilakukan hingga saat ini.

Amerika Serikat dan negara-negara Eropa telah membentuk kelompok kerja untuk pengembangan teknologi pirolisis Bioenergi, Badan Energi Internasional sejak tahun 1995 sampai sekarang masih melanjutkan pengembangan teknologi tersebut. Amerika Serikat juga telah melakukan program biomassa multi-year sejak tahun 2007. Dalam program ini, pirolisis biomassa kayu diposisikan sebagai salah satu teknologi kunci untuk produksi bio-fuel. Badan Energi Internasional dan Departemen Energy Amerika Serikat fokus pada pengembangan teknologi pirolisis cepat (fast Pyrolysis), karena produksi bio oil yang dihasilkan tinggi dan dapat diproduksi dengan metode pirolisis ini. Oleh karena itu, 
berbagai upaya untuk teknik pengembangan sistem pasokan bahan baku yang berkelanjutan yang dibuat untuk menurunkan biaya produksi bahan bakar bio-fuel dengan harga bahan bakar fosil. Dengan demikian, alat pirolisis diperlukan dalam skala besar.

Teknologi pirolisis sudah lama dikembangkan, tapi proses yang terjadi selama pirolisis tidak sepenuhnya dapat dijelaskan secara rinci sampai sekarang. Pirolisis adalah proses penguraian biomassa dengan metode pemanasan dari fase padat ke gas dan fase cair. Banyak pengujian yang telah dilakukan untuk menyelidiki hasil gas, arang dan tar dengan berbagai metode pirolisis kayu pada masa sekarang ini. dan review jurnal juga telah dipublikasikan [2]. Di sisi lain, untuk pemahaman dasar dari proses pirolisis, parameter kimia kinetik proses dekomposisi termal diperoleh oleh beberapa peneliti, dan persamaan kinetik berasal dari bentuk yang disederhanakan. Hal ini juga diketahui bahwa kayu terdiri dari tiga komposisi utama, selulosa, hemiselulosa, dan lignin, tetapi ada banyak komposisi kecil lainnya yang terkandung di dalam biomassa, seperti ekstraktif organik dan mineral [4]. persamaan kinetik diidentifikasi untuk masing-masing komposisi utama [5], tetapi rasio komposisi bervariasi antara satu kayu dengan kayu lainnya, dan persamaan kinetik komposisi minor tidak tersedia. Akibatnya, tidak ada persamaan kinetik yang unik yang dapat mengungkapkan proses pirolisis secara keseluruhan.

Negara-negara berkembang juga ambil bagian dalam memperlambat atau mencegah perubahan iklim, pemanasan global dan dalam mengatasi krisis energi bersama-sama dengan negara-negara maju. Negaranegara berkembang memiliki rencana untuk mengembangkan energi terbarukan menggunakan sumber daya alam mereka. Namun, krisis energi menjadi semakin serius, karena negara-negara berkembang pasti akan menggunakan lebih banyak energi di masa depan dibandingkan tahun-tahun terakhir. negara berkembang memiliki masalah energi lain yang tingkat kelistrikan yang rendah. negara berkembang memiliki masalah energi lain yang tingkat kelistrikan yang rendah. Menurut estimasi oleh IEA pada tahun 2011 [6], rata-rata tingkat Kelistrikan di dunia adalah $80,5 \%$. Namun, kelistrikan di negara berkembang adalah $75 \%$. Terutama, di daerah desa terpencil, 32\% masyarakat tidak dapat mengakses listrik. Melihat negara-negara ASEAN, kelistrikan di Indonesia adalah $76 \%$ pada tahun 2012, yang sangat rendah dari negara Asia lainnya, Vietnam $(89,3 \%)$, Filipina $(89,7 \%)$, Thailand $(99,3 \%)$, Malaysia $(99,4 \%)$, dan Singapura (100\%). Kelistrikan di seluruh Indonesia masih rendah, namun, di daerah perkotaan seperti Jakarta dan sumatera Utara lebih dari $90 \%$ dari orang-orang dapat mengakses listrik, sementara hanya $50 \%$ dari wilayah masyarakat pedesaan dapat mengakses listrik. Di daerah perkotaan, listrik biasanya dipasok melalui jaringan listrik dari pembangkit listrik skala besar. Banyak daerah pedesaan di negara-negara berkembang tidak dapat dijangkau jaringan listrik. Membangun jaringan listrik untuk daerah pedesaan, yang baru, tidak efisien dan terlalu mahal. Oleh karena itu, sistem pembangkit jaringan listrik mendapat perhatian yang besar untuk meningkatkan kelistrikan di daerah pedesaan, karena efisiensi dan mudah.

Namun, seperti yang dijelaskan di atas, teknologi biomassa skala besar canggih yang dikembangkan oleh Amerika Serikat dan negara-negara Eropa tidak selalu diperlukan untuk daerah desa terpencil, karena pemeliharaan yang rumit sehingga tidak tersedia tenaga yang handal dalam pemeliharaan teknologi tersebut. Sistem yang sederhana dan pemeliharaan yang mudah yang diperlukan di daerah desa terpencil. Ada beberapa metode untuk membuat reaktor hampa udara atau kondisi udara yang sangat kecil untuk proses pirolisis kayu. Metode pertama Menghilangkan udara dalam reaktor pirolisis dengan mengisi gas inert seperti nitrogen, metode kedua yaitu kondisi oksigen yang sangat sedikit dengan cara menumpuk bahan baku diatas bahan bakar, dan metode lainnya dengan kondisi hampa udara yaitu dengan memindahkan udara dalam reaktor dengan menggunakan pompa vakum yang banyak digunakan untuk biomassa pirolisis. Dua metode sebelumnya sangat cocok untuk sistem skala besar demi efisiensi yang tinggi. Namun, dibutuhkan proses kembali untuk membersihkan produk pirolisis, seperti menghilangkan partikel halus, atau membersihkan bio oil $[15,16]$. Di sisi lain, proses vacum pirolisis telah dikembangkan untuk mengkonversi biomassa untuk bio fuel. Beberapa kelemahan yang ditunjukkan untuk keperluan industri, tetapi meskipun memiliki kekurangan, vakum pirolisis memang memiliki keuntungan yang menarik: produksi minyak bersih dan penggunaan bahan baku dalam ukuran yang besar [6].

Penelitian ini bertujuan meningkatkan kelistrikan di daerah desa terpencil menggunakan generasi mesin gas pirolisis. Sebuah teknologi baru dari pirolisis kayu karet dengan metode pengosongan udara sebelum proses berjalan, metode ini memberikan keuntungan yaitu memperoleh gas yang bersih dari campuran udara, sehingga dapat digunakan untuk mesin generator gas. Dalam teknologi baru pirolisis ini, tidak diperlukan perlakuan awal untuk bahan baku dan perlakuan akhir untuk gas pirolisis tersebut, dan sistem ini sederhana dan sedikit perawatan. Dalam paper ini, kinerja sistem pirolisis dievaluasi dengan serangkaian percobaan.

\section{Material, alat dan prosedur penelitian 2.1. Material}

Di wilayah sumatra banyak terdapat perkebunan karet baik perusahaan maupun perorangan. Pohon karet yang sudah tua dan tidak mampu menghasilkan karet lagi, maka akan ditebang. Kayu tersebut kemudian diolah menjadi furniture dengan proses pengeringan yang terukur, sehingga kadar air yang dimiliki kayu karet dapat dikurangi sampai batas minimum. Penelitian ini menggunakan kayu karet sisa dari pengolahan pabrik furniture yang tidak bisa dimanfaatkan lagi, karena potongan-potongan kayu tersebut bervariasi. Oleh karena itu penulis ingin memakai kayu karet tersebut untuk dijadikan sampel proses pirolisis. Pada penelitian ini sampel kayu karet yang diuji pada tabung reaktor adalah $5 \mathrm{~kg}, 3 \mathrm{~kg}, 1 \mathrm{~kg}$ dan $0.1 \mathrm{~kg}$ per proses. Beberapa potongan-potongan kayu yang ditunjukkan pada 
Gambar. 2.1. Potongan dimensi dirangkum dalam Tabel 2.1

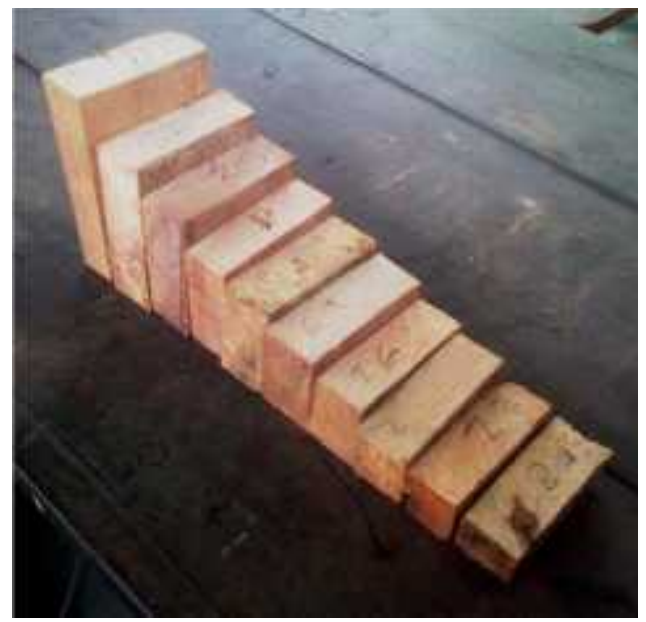

Gambar.2.1. Potongan kayu dari pabrik furnitur

Tabel 2.1. Dimensi potongan kayu dari pabrik furnitur

\begin{tabular}{cccc}
\hline No kayu & $\begin{array}{c}\text { Tinggi } \\
(\mathrm{mm})\end{array}$ & $\begin{array}{c}\text { Lebar } \\
(\mathrm{mm})\end{array}$ & $\begin{array}{c}\text { Panjang } \\
(\mathrm{mm})\end{array}$ \\
\hline 1 & 127 & 85 & 30 \\
2 & 100 & 85 & 30 \\
3 & 83 & 85 & 28 \\
4 & 70 & 85 & 32 \\
5 & 65 & 85 & 32 \\
6 & 54 & 85 & 29 \\
7 & 41 & 85 & 30 \\
8 & 35 & 85 & 32 \\
9 & 30 & 85 & 30 \\
10 & 22 & 85 & 30 \\
\hline
\end{tabular}

\subsection{Alat pengujian pirolisis kayu dan bagian- bagiannya}

Alat pengujian pirolisis kayu dikembangkan di laboratorium. Alat tersebut ditunjukan pada gambar 2.2. Sistem ini memiliki 5 komponen utama yaitu tungku pembakaran, tabung reaktor, kondensor, tabung filter dan tempat tabung penyimpanan gas yang ditunjukkan dari kiri ke kanan. (gambar 2.2a)

reaktor hampa udara ditempatkan di dalam tungku pembakaran. Ruang reaktor terbuat dari pipa stainless steel dengan diameter dalam adalah $254,0 \mathrm{~mm}$, ketebalan dinding adalah 13,0 mm, dan tinggi adalah 500,0 mm. Pada bagian atas ruang reaktor dipasang penutup yang diikatkan dengan baut untuk bisa membuka bagian atas dari reaktor, sebelum memasukkan kayu karet kedalam reaktor harus dipastikan tidak ada material arang sisa pirolisis atau material lainnya.

Semua komponen dari sistem terhubung dengan pipa stainless steel diameter $1 / 2$ inci. Dalam kondensor, gas yang mengandung uap tar didinginkan dengan air yang mengalir sehingga terjadi kondensasi dan tar yang terkondensasi akan mengendap di bagian bawah kondensor. Karbondioksida dan unsur kimia lain yang tidak terkondensasi akan melewati tabung air secara langsung bersentuhan, sehingga semua Carbondioksida dapat mengendap dan bercampur dengan air, setelah melewati tabung air tersebut gas yang sudah difilter menghasilkan gas yang bersih tanpa adanya kotoran hasil pirolisis.

Sebelum memulai eksperimen, ruang reaktor, kondensor (perangkap tar), tabung air (perangkap $\mathrm{CO}_{2}$ ) dan tangki penyimpanan gas di vakum menggunakan pompa vakum hingga - 0,02 MPa (-0,2 atm). Kemudian, katup antara ruang reaktor dan kondensor (perangkap tar) tar ditutup. T1, T2, dan T3 yang ditunjukkan pada Gambar 1 (b) menunjukkan posisi di mana Thermokopel tipe $\mathrm{K}$ dipasang.

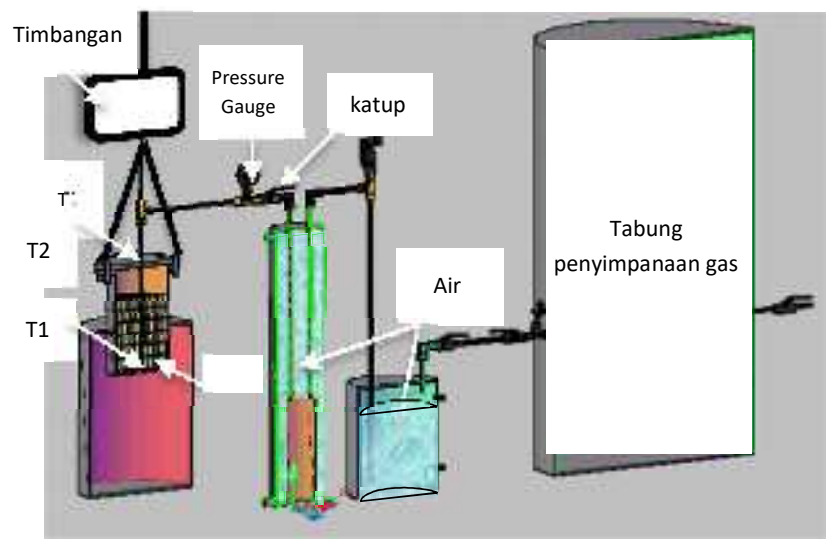

\section{Desain sistem alat pengujian}

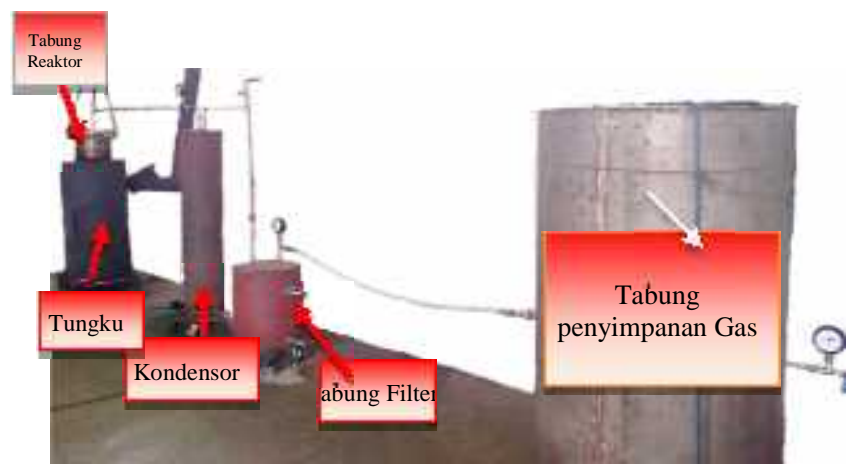

Gambar 2.2. Konstruksi alat penelitian

\subsection{Langkah-langkah penelitian}

Adapun langkah-langkah dalam penelitian ini sebagai berikut:

1. Potongan-potongan kayu sejumlah $(5 \mathrm{~kg}, 3 \mathrm{~kg}, 1 \mathrm{~kg}$, dan $0,1 \mathrm{~kg}$ ) dimasukkan kedalam tabung reaktor

2. Dua buah termokopel tipe $\mathrm{K}$ dipasang di dalam tabung reaktor yaitu pada bagian bawah dan atas. Kemudian tabung reaktor ditutup dengan tutup stainless steel dan dikunci dengan baut untuk mencegah kebocoran. Selanjutnya pada bagian atas penutup dipasang termokopel tambahan seperti yang ditunjukkan pada gambar 2.2a.

3. Katub yang menghubungkan ke tabung penyimpanan gas ditutup, kemudian tabung di vacuum terlebih dahulu untuk membuang udara di dalam tabung, agar gas yang dihasilkan tidak terkontaminasi dengan udara. Selanjutnya Tabung reaktor, Kondensor, tabung filter dan pipa penghubung juga divacuum dengan pompa vacuum 
untuk menghilangkan udara pada alat pengujian. Tekanan di dalam alat pengujian setelah di vacuum berada pada -0.08 MP atau 0.02 pada tekanan absolut. Setelah semua di vacuum dilakukan pengecekan untuk memastikan bahwa tidak ada kebocoran yang menyebabkan udara kembali masuk kedalam alat pengujian. Setelah dipastikan tidak ada kebocoran semua katup pada alat penelitian di tutup.

4. Berat tabung yang sudah berisi $5 \mathrm{~kg}$ potongan kayu karet di ukur dengan timbangan digital dengan presisi 50 gram selama dilakukan penelitian.

5. Tabung reaktor yang berisi kayu tersebut dipanaskan dari tungku pembakaran yang terletak dibawahnya dengan menggunakan bahan bakar kayu karet juga.

6. Temperatur pada tiga titik, tekanan dan penurunan massa dari kayu di ukur setiap menit.

7. Pemanasan di tungku pembakaran di jaga api agar tetap stabil dan merata.

8. Setelah tekanan di dalam tabung reaktor mencapai tekanan (0.1 atau 0.2 MPa), maka katup antara tabung reaktor dan kondensor dibuka pelan-pelan agar tidak terjadi penurunan tekanan dibawah tekanan yang diharapkan, kemudian tekanan dijaga konstan sampai berakhirnya penelitian.

9. Penelitian dianggap selesai apabila pada timbangan digital tidak terjadi lagi penurunan massa. Setelah proses pirolisis selesai, arang di dalam tabung reaktor, tar yang mencair di kondensor serta massa gas yang dihasilkan di dalam tabung penyimpanan di timbang menggunakan timbangan digital.

Sistem ini ditandai dengan menghilangkan udara pada alat sebelum proses pirolisis dimulai, pada saat proses pirolisis dimulai pompa vacuum tidak dipergunakan lagi. Hal inilah yang dimaksud dengan metode hampa udara pada jurnal ini. Sistem ini berbeda dengan pirolisis vacuum, dimana selama proses pirolisis kontinu di vacuum. [8]

\section{Hasil Pengujian}

Data hasil penelitian yang diukur dan diamati adalah Temperatur, tekanan dan penurunan massa. Setelah percobaan, massa arang, tar dan gas diukur. Berikut hasil penelitian yang ditunjukkan pada subbagian dibawah ini.

\subsection{Temperatur}

Suhu diukur di tiga titik seperti yang ditunjukkan pada Gambar 2.2. Pengukuran temperatur di tiga titik yang ditunjukkan pada Gambar 2, untuk kasus kayu 5.0 $\mathrm{kg}$ dan tekanan tabung reaktor $0,1 \mathrm{MPa}$. Pada kondisi yang sama, tiga percobaan dilakukan. hasil penelitian rata-rata ditunjukkan pada gambar 2. Pada Gambar 2 (T1), suhu di bagian bawah tabung reaktor diplot sebagai fungsi waktu (menit) setelah tungku pembakaran dipanaskan. Pada bagian bawah diluar tabung reaktor api membakar secara langsung. Temperatur bagian bawah dalam tabung reaktor meningkat hampir linear terhadap waktu hingga temperatur $389^{\circ} \mathrm{C}$. Lalu, temperatur turun kembali hingga $244^{\circ} \mathrm{C}$. Setelah penurunan tersebut, temperatur perlahan naik kembali ke grafik semula. Namun, setelah temperatur $497{ }^{\circ} \mathrm{C}$, kenaikan temperatur cenderung lambat kenaikannya dan mencapai maksimum sekitar $603{ }^{\circ} \mathrm{C}$. Proses pirolisis selesai setelah 100 menit berjalan.

Temperatur pada bagian atas ruang di dalam tabung reaktor lebih rendah dari suhu di bagian bawah seperti yang ditunjukkan pada Gambar 2 (T2). Temperatur maksimum $345{ }^{\circ} \mathrm{C}$ pada menit 63 menit, tidak seperti temperatur di bagian bawah yang mengalami penurun tiba-tiba. Kemudian, suhu secara bertahap menurun sampai berakhirnya pengujian. Temperatur di atas permukaan tutup tabung reaktor ditunjukkan pada Gambar 2 (T3). Kenaikan temperatur dengan waktu hampir mengikuti grafik pada temperatur bagian atas, walaupun nilai maksimum lebih rendah yaitu $256{ }^{\circ} \mathrm{C}$ pada menit 63 .

Pada Gambar 3, perubahan temperatur dari tiga titik pengukuran temperatur dengan perbedaan 0,1 dan 0,2 $\mathrm{MPa}$ tidak terdapat perbedaan yang signifikan. Dapat disimpulkan bahwa tekanan tidak memiliki pengaruh yang signifikan terhadap perubahan temperatur.

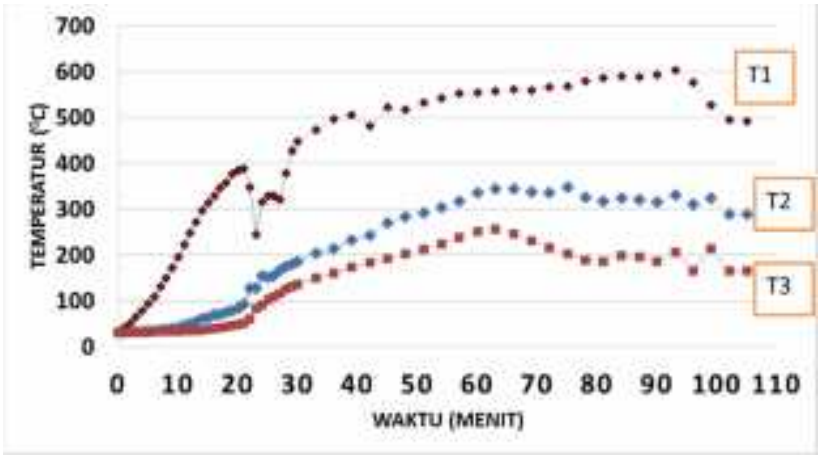

Gambar 2. Pengukuran temperatur rata-rata pada tiga titik (T1, T2, T3), pengujian kayu karet $5 \mathrm{~kg}$ dan tekanan $0.1 \mathrm{MPa}$

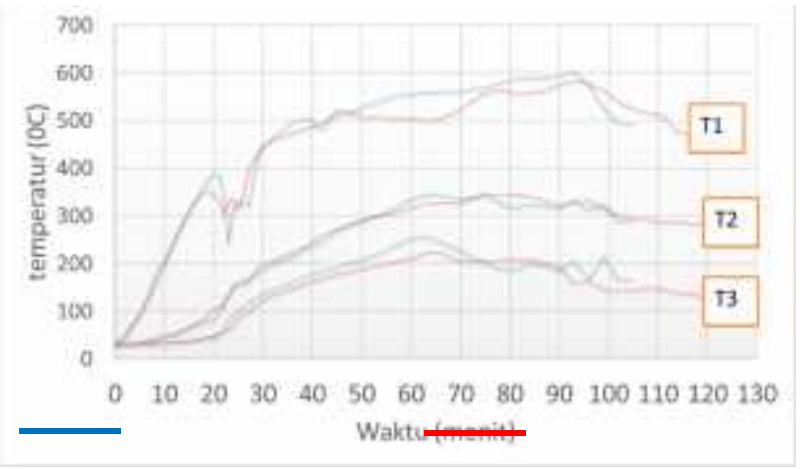

Gambar 3. Pengukuran temperatur rata-rata pada tiga titik (T1, T2, T3) pada tekanan 0.1 MPa dan 0.2 MPa.

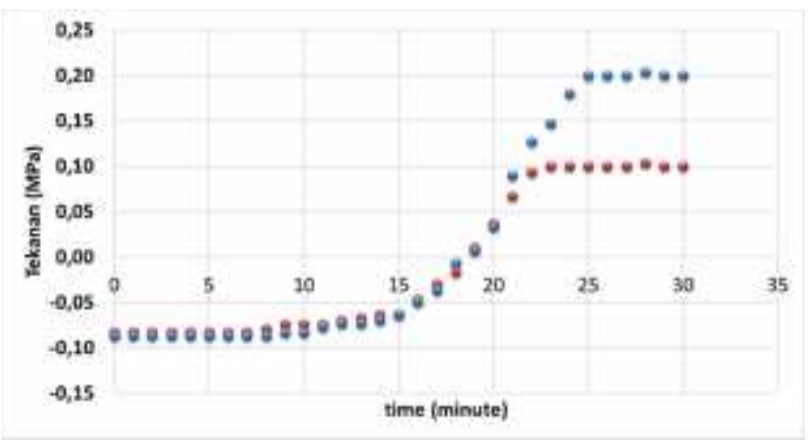


Gambar 4. tekanan vs waktu dalam tabung reaktor untuk $0.1 \mathrm{MPa}$ dan $0.2 \mathrm{MPa}$ dan $5 \mathrm{~kg}$ kayu karet.

\subsection{Tekanan}

Pressure gauge di tabung reaktor diplot sebagai fungsi waktu pada Gambar 4. tekanan awal tabung setelah di vacuum adalah -0,09 $\mathrm{MPa}$. Selama 8 menit pada awal percobaan, tekanan tidak mengalami perubahan, menit ke 8 sampai menit ke 15 kenaikan tekanan masih lambat, setelahnya kenaikan tekanan naik drastis sampai tekanan $0.1 \mathrm{MPa}$ atau 0.2 $\mathrm{MPa}$. Sebelum katup terbuka pada tekanan 0,1 MPa, perubahan tekanan kedua variasi $(0.1$ $\mathrm{MPa}$ dan 0.2 MPa) waktu harus sama dalam kedua kasus.

Kenaikan tekanan dari tabung reaktor dapat disebabkan oleh dekomposisi termal dari potongan kayu menjadi gas pirolisis dan ekspansi termal gas di dalam tabung reaktor. Tekanan dari tabung reaktor dipertahankan konstan 0,1 atau 0,2 MPa lebih dari 100 menit, sampai proses pirolisis dalam tabung reaktor selesai.

\section{3. hasil proses pirolisis}

Setelah proses pirolisis selesai dalam tabung reaktor tersebut yang ditandai oleh tidak adanya penurunan berat berbanding waktu. Kemudian, arang dalam tabung reaktor, tar dalam kondensor, dan gas dalam tabung penyimpanan masing-masing di timbang. Perlu diketahui bahwa gas yang tersimpan di dalam tabung penyimpanan tidak semua gas yang dihasilkan oleh proses pirolisis, karena sejumlah karbon dioksida dan unsur kimia lain telah dihapus oleh tabung filter. hasil timbangan disajikan dalam Tabel 1. Dalam tabel ini, nilai dalam kurung adalah persentase.

Dari Hasil pirolisis dengan kayu $5.0 \mathrm{~kg}$ dapat dilihat bahwa hasil dari tar, arang, dan gas masingmasing sekitar 40\%, 30\%, dan 30\% dari berat kayu. Alat pengujian ini menghasilkan tar sedikit lebih tinggi daripada hasil lainnya.

\section{Pembahasan}

Penelitian ini bertujuan untuk meningkatkan kelistrikan di daerah des terpencil, salah satu alat pengujian dari sistem pirolisis kayu telah dikembangkan berdasarkan pada teknologi baru dalam skala laboratorium. Dalam rangka untuk memastikan penggunaan yang berkelanjutan, peralatan yang mudah pemeliharaan tidak bisa dihindari. Berdasarkan konsep ini, alat tersebut dibuat dan kinerjanya dievaluasi. Berbeda dengan metoda pirolisis lain yang menggunakan bahan baku ukuran kecil seperti pelet kayu dan dengan proses pirolisis cepat, alat ini menggunakan potonganpotongan kayu yang agak besar dan proses pirolisis lambat. Oleh karena itu, ada beberapa faktor yang mendominasi kinerja alat pirolisis ini. Dalam subbagian berikutnya, faktor-faktor tersebut akan dibahas.

Tabel 2. Hasil pirolis $5 \mathrm{~kg}$ kayu dan tekanan 0.1 MPa dan 0.2 MPa.

\begin{tabular}{cccccc}
\hline $\begin{array}{c}\text { Berat kayu } \\
(\mathrm{Kg})\end{array}$ & $\begin{array}{c}\text { Tekanan( } \\
\mathrm{MPa})\end{array}$ & $\begin{array}{c}\text { Tar kg } \\
(\mathrm{wt} \%)\end{array}$ & $\begin{array}{c}\text { Arang kg } \\
(\mathrm{wt} \%)\end{array}$ & $\begin{array}{c}\text { Gas kg } \\
(\mathrm{wt} \%)\end{array}$ & $\begin{array}{c}\mathrm{CO}_{2} \text { \& gas lainnya kg } \\
(\mathrm{wt} \%)\end{array}$ \\
\hline 5 & 0.1 & $1.96(39.2)$ & $1.43(28,6)$ & $1.13(22.6)(32.2)^{*}$ & $0.47(9.6)$ \\
\hline
\end{tabular}

* $\mathrm{CO}_{2}$ dan gas lainnya telah di filter di tabung filter.

\subsection{Pengaruh Tekanan}

Tekanan tabung reaktor dimonitor selama percobaan. Setelah tekanan tabung reaktor mencapai tekanan 0,1 $\mathrm{MPa}$, atau 0,2 $\mathrm{MPa}$ tekanan tabung reaktor dipertahankan konstan pada level tersebut sampai proses pirolisis berakhir. Ini dimaksudkan bahwa potonganpotongan kayu dapat mengalami dekomposisi termal di bawah tekanan konstan. Seperti yang terlihat pada Gambar 3, meskipun tekanan tabung reaktor berubah antara 0,1 $\mathrm{MPa}$ dan 0,2 $\mathrm{MPa}$, suhu di tiga titik dari tabung reaktor bervariasi sama terhadap waktu. Selain itu, hasil pirolisis ditunjukkan pada Tabel 2 mengindikasikan bahwa tidak ada perbedaan yang signifikan antara dua tingkat tekanan. Hal ini dapat diambil dari hasil pengujian bahwa tekanan tabung reaktor hingga $0,2 \mathrm{MPa}$ tidak mempengaruhi proses dekomposisi termal kayu di dalam tabung reaktor.
Tabel 2 Komposisi kimia penyusun gas hasil pirolisis

\begin{tabular}{lccc}
\hline \multicolumn{3}{c}{ Gas vol\% } & \multicolumn{3}{c}{ Massa Kayu (kg) } \\
& 1 & 3 & 5 \\
\hline $\mathrm{H}_{2}$ & 17.1 & 19.5 & 19.8 \\
$\mathrm{CH}_{4}$ & 32.2 & 37.7 & 36.6 \\
$\mathrm{CO}$ & 28.9 & 22.1 & 18.6 \\
$\mathrm{CO}_{2}$ & 21.8 & 20.7 & 14.9 \\
\hline
\end{tabular}

\subsection{Pengaruh massa kayu}

Massa kayu yang dimasukkan ke dalam tabung reaktor menjadi salah satu faktor yang paling dominan untuk menentukan kinerja dari alat pengujian. Massa kayu $5.0 \mathrm{~kg}$ yang diisi ke dalam tabung reaktor kurang lebih setengah dari total ketinggian tabung. Kemudian, tabung reaktor diletakkan ke dalam tungku pembakaran hingga kedalaman 300,0 mm dari bawah tabung reaktor. 
Ini berarti bahwa semua potongan-potongan kayu masuk ke dalam tungku pembakaran.

Untuk massa kayu $0,1 \mathrm{~kg}, 1,0 \mathrm{~kg}$, dan $3,0 \mathrm{~kg}$ pengujian juga dilakukan untuk melihat pengaruh massa kayu terhadap produk pirolisis, dengan pengujian tekanan pada 0,2 MPa. Tingkat pemanasan hampir sama dalam empat kasus termasuk massa kayu $5.0 \mathrm{~kg}$.

Tiga hasil pirolisis utama diplot sebagai fungsi dari massa kayu pada Gambar 5. Untuk massa kayu lebih dari $1,0 \mathrm{~kg}$, tiga hasil yang sensitif terhadap tuduhan kayu. Namun, perlu dicatat bahwa unuk pengujian $0,1 \mathrm{~kg}$ massa kayu, hasil tar secara signifikan rendah sementara hasil gas sangat tinggi Alasan berikut dapat dipertimbangkan untuk fakta berikut. Berat kayu $0,1 \mathrm{~kg}$ adalah volume yang sangat kecil dibandingkan dengan volume dari tabung reaktor. ketika gas mulai menguap dari kayu, volume gas yang menguap tidak mampu menaikkan tekanan hingga 0.2 $\mathrm{MPa}$, sehingga uap gas dipanaskan terus hingga lebih dari $500^{\circ} \mathrm{C}$, yang mengakibatkan perubahan komposisi kimia dan menghasilkan gas kompresibel semakin meningkat.

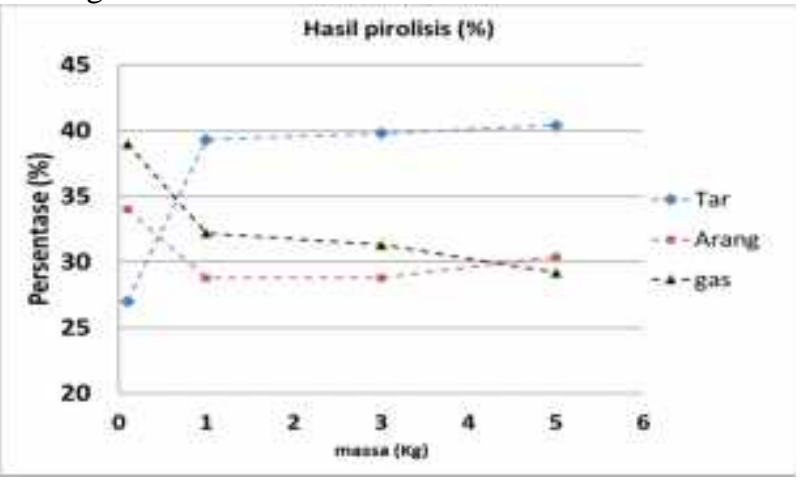

Gambar 5. Hasil pirolisis vs massa kayu

\subsection{Komposisi gas}

Komposisi utama dari hasil pirolisis kayu biasanya hidrogen, metana, karbon monoksida, dan karbon dioksida. produk gas dari massa kayu 1,0, 3,0, dan 5,0 dianalisa dengan gas kromatografi. Hasil pengujian ditampilkan dalam Tabel 2. Seperti yang terlihat dalam tabel ini, rasio komposisi empat gas tidak berpengaruh secar signifikan terhadap massa kayu. Komposisi utama yaitu gas metana. Sedangkan komposisi gas lain hampir sama volumenya. Konsentrasi metana sangat tinggi dibandingkan dengan hasil peneliti lain [1], di mana konsentrasi metana diberikan dalam wt $\%$, dan dikonversi menjadi $15,5 \%$ vol dengan perhitungan. percobaan pirolisis dilakukan oleh peneliti lain menggunakan kayu karet sama dengan yang digunakan dalam penelitian ini, tetapi potongan-potongan kayu berukuran kecil yaitu kurang dari 10,0 mm kubik, dan peralatan yang digunakan berbeda yang dapat dipanaskan sampai $900{ }^{\circ} \mathrm{C}$. Hasil eksperimen menunjukkan bahwa proses pirolisis memproduksi gas dengan kandungan metana dari 17,6\%, 19,8\%, 18,0\% dan $10,1 \%$ pada pirolisis temperatur dari $600{ }^{\circ} \mathrm{C}, 700{ }^{\circ} \mathrm{C}$, $800{ }^{\circ} \mathrm{C}$, dan $900{ }^{\circ} \mathrm{C},[19,20]$.

Hal ini tidak jelas mengapa alat pengujian ini dapat menghasilkan gas yang kaya metana. Dua faktor dapat dipertimbangkan untuk alasan tersebut. Salah satunya adalah jenis kayu dan yang kedua adalah sistem pirolisis. Penelitian lebih lanjut diperlukan untuk memperjelas masalah ini. Selain itu, nilai kalor dari gas yang dihasilkan oleh alat pengujian ini dihitung sebesar 9,7 MJ / kg dari hasil di Tabel 1 dan 2. nilai kalor gas ini juga lebih tinggi dari gas kayu pirolisis lainnya [21]. Jika karbon dioksida benar-benar dihapus oleh tabung filter, nilai pemanasan naik ke 19,0 MJ / kg. Ini hampir sama dengan nilai kalor kayu kering [11].

\section{Kesimpulan}

Terdapat beberapa kesimpulan yang dapat ditarik dari hasil pengujian ini yaitu:

Alat ini ditandai dengan metode hampa udara di dalam alat sebelum proses pirolisis berjalandi mana kayu mengalami dekomposisi termal dalam ketiadaan oksigen.

Tingkat tekanan tabung reaktor di kondisikan pada 0,1 MPa dan 0,2 MPa dimana hasil proses pirolisis tidak berbeda secara signifikan hasil pirolisis dari tar, arang, dan gas.

Massa kayu 1,0 kg, 3,0 kg dan 5,0 kg diuji di tabung reaktor tidak mempengaruhi hasil pirolisis.

Namun untuk massa $0,1 \quad \mathrm{~kg}$ massa kayu menghasilkan kandungan gas yang lebih tinggi dibandingkan dengan tar dan arang. Hal ini dapat asumsikan sebagai hasil dekomposisi kedua dari tar. Selain itu, hasil ini menunjukkan bagaimana untuk mengembangkan dan memodifikasi alat untuk hasil gas yang lebih tinggi.

Alat ini menghasilkan lebih banyak gas pirolisis Metana. Sebagai hasilnya, nilai panas dari gas pirolisis adalah sekitar 9,7 MJ / kg untuk gas, namun apabila karbondioksida dan gas lain benar-benar dapat difilter secara maksimal di tabung filter, maka nilai energinya dapat mencapai $19,0 \mathrm{MJ} / \mathrm{kg}$.

Daftar pustaka

[1] M. Bajus, "Pyrolysis of Woody Material," Petroleum \& Coal, Vol. 53, No. 3, 2010, pp. 207214.

[2] A. Demirbas, "Biorefineries: Current Activities and Future Developments," Energy Conversion and Manage-ment, Vol. 50, No. 11, 2009, pp. 27822801.

http://dx.doi.org/10.1016/j.enconman.2009.06.035

[3] B. M. Wagenaar, W. Prins and W. P. M. Swaaij, "Flash Pyrolysis Kinetics of Pine Wood," Fuel Processing Technology, Vol. 36, No. 1-3, 1993, pp. 291-298.

http://dx.doi.org/10.1016/0378-3820(93)90039-7

[4] P. Wild. "Biomass Pyrolysis for Chemicals," Doctor Thesis, University of Groningen, Groningen, 2011.

[5] L. Gasparovic, Z. Korenova and L. Jelemensky, "Kinetic Study of Wood Chips Decomposition by TGA," Pro-ceedings of 36th International Conference of Slovak So-ciety of Chemical Engineering, Tatranské Matliare, 25-29 May 2009, pp. 178-1-178-14. 
[6] World Energy Outlook 2011, International Energy Agency, 2011. http://www.worldenergyoutlook.org/resources/ener gydevelopment/accesstoelectricity/

[6] M. Ringer, V. Putsche and J. Scahill, "Large-scale Pyro- lysis oil production: A Technology Assessment and Economic Analysis," Technical Report NREL/TP-510-3779, National Renewable Energy Laboratory, US Department of Energy, November 2006.

[7] A. V. Bridgwater, "The Future for Biomass Pyrolysis and Gasification: Opportunities and Poslicies for Europe," 2002.

http://ec.europa.eu/energy/renewables/studies/doc/b ioenergy/2002_report_p536.pdf

[8] M. Garcia-Perez, P. Lappas, P. Hughes, L. Dell, A. Cha- ala, D. Kretschmer and C. Roy, "Evaporation and Combustion Characteristics of Biomass Vacuum Pyrolysis Oils," IFRF Combustion Journal, 2006, Article ID: 200601.

[9] L. Fagbemi, L. Khezami and R. Capart, "Pyrolysis Products from Different Biomasses: Application to the Ther- mal Cracking of Tar," Applied Energy, Vol. 69, No. 4, 2001, pp. 293-306. http://dx.doi.org/10.1016/S0306-2619(01)00013-7

[10] T. B. Read, E. Anselmo and K. Kircher, "Testing \& Modeling the Wood-Gas Turbo-Strove," Thermochemical Biomass Conversion Conference, 17-20 September 2000, Tyrol, pp. 693-704.

[11] Biomass Energy Data Book, US Department of Energy, Appendix A, 2011. http://cta.ornl.gov/bedb/index.shtm 